\title{
Systematic screening: A strategy for determining and meeting clients' reproductive health needs
}

\author{
James R. Foreit
}

Population Council

Follow this and additional works at: https://knowledgecommons.popcouncil.org/departments_sbsr-rh

Part of the Demography, Population, and Ecology Commons, Family, Life Course, and Society

Commons, International Public Health Commons, Medicine and Health Commons, and the Quantitative, Qualitative, Comparative, and Historical Methodologies Commons How does access to this work benefit you? Let us know!

\section{Recommended Citation}

Foreit, James R. 2006. "Systematic screening: A strategy for determining and meeting clients' reproductive health needs," FRONTIERS Program Brief. Washington, DC: Population Council. 


\section{Systematic Screening: \\ A Strategy for Determining and Meeting Clients' Reproductive Health Needs}

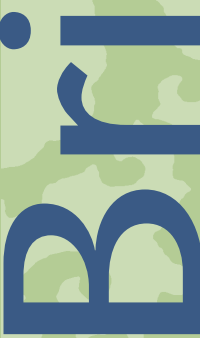

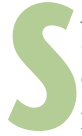
ystematic screening is a strategy to integrate reproductive health services at the provider level. Integration is defined as the proactive provision of multiple reproductive health services in the same facility at the same time (Foreit, Hardee, and Agarwal 2002). Systematic screening is a simple intervention to increase the number of services received at a single client visit. In this strategy, providers use a checklist or brief questionnaire to identify each client's needs and desires for reproductive health services. They then provide these services to her during the same visit, through an appointment at the same clinic, or through referral to another facility. This solution is embodied in the recommendation of the 1994 Cairo International Population and Development Conference's Programme of Action to promote the delivery of integrated reproductive health services.

Operations research (OR) studies in Latin America provided evidence of the benefits of systematic screening in terms of

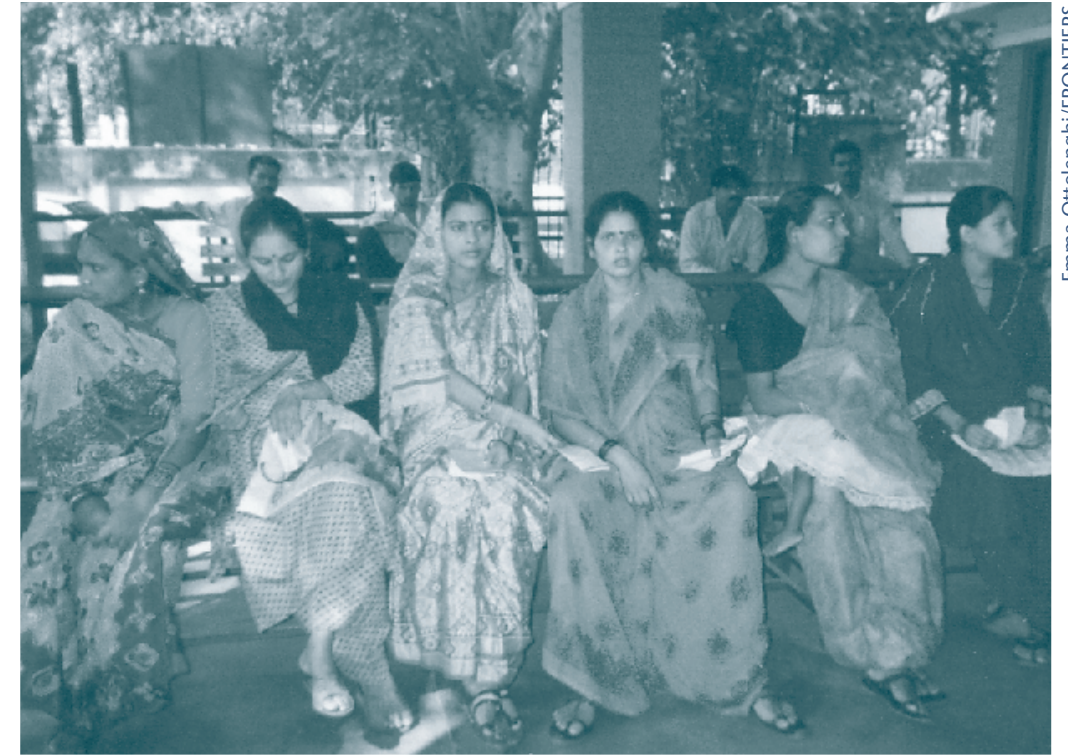

Women waiting for services at an Indian clinic

increased services, increased attention to unmet needs, and greater cost-effectiveness. Studies in Guatemala and Mexico showed that client screening resulted in greater information given to clients as well as important improvements in the use of services (Vernon and Foreit 1999). In a study in Peru, the screening intervention increased the number of services provided per client visit by 13 percent (León et al 1998). Based on the success of these inter- ventions, the Population Council's Frontiers in Reproductive Health Program (FRONTIERS) conducted an interregional test of systematic screening in four countries in sub-Saharan Africa, Asia, and Latin America.

This Program Brief discusses the results of these four FRONTIERS OR studies on systematic screening in Bolivia, Honduras, India and Senegal. The objectives of the studies were to: (1) determine the

Systematic screening is a simple intervention to increase the number of health care needs addressed during a single client visit.

When implemented fully, systematic screening increased the number of services received per client visit by 9 to 24 percent.

- Systematic screening can improve women's health by addressing multiple unmet needs for reproductive and other health services. 


\section{What is systematic screening?}

Systematic screening is a technique to reduce the unmet health care needs of clients by increasing the number of services provided per client per visit. The intervention consists of three steps:

1. Use a standardized instrument (set of questions) to identify each client's needs for additional reproductive, child or other health services.

2. Offer the services to meet the identified needs during the same visit.

3. Offer a future appointment or referral for those services that cannot be provided immediately.

effectiveness of screening in different regions and service delivery points, where the measure of success was the number of health services per client visit; (2) identify major barriers to screening; and (3) test the effectiveness of different screening materials and techniques.

\section{Why screen for unmet needs?}

Many clients, especially women with young children, have multiple needs for preventive and curative reproductive and child health services. These may include family planning, health and nutritional assessments related to pregnancy, and screening, treatment, or counseling for sexually transmitted infections. Typically, health providers deliver only the service explicitly requested by the client and do not identify other needs. Clients may be unaware that they need additional services, or that the services they need are available. For example, data from the 1998 Senegal Situation Analysis indicated that the majority of family planning clients received little or no information about other reproductive health issues, and that family planning was mentioned to only 12 percent of antenatal clients during the consultation $(\mathrm{MOH}$ and Population Council 1998). In any case, the client often leaves the facility with unmet reproductive or child health needs, and the service provider misses an opportunity to render those services.

\section{Methodology}

The studies in each of the four countries used a similar design and screening instrument based on a standard protocol (Foreit et al. 2003). The study in India used a pre- and post-intervention experimental design that compared intervention and control sites. The studies in Bolivia, Honduras, and Senegal used simple "before and after" designs to compare the number of services received per client visit.

In Latin America, the studies took place in a remote rural health network (Bolivia) and in an urban area (Honduras). In India and Senegal, the studies tested the screening instrument in both urban and rural service delivery sites. Research designs and procedures used in the systematic screening studies responded to requests for shorter, less expensive operations research. The studies ranged in duration from 12 to 18 weeks, and were conducted at a relatively low cost.

The systematic screening instrument is a one-page form. The provider who first registers the client at the facility uses the form to identify services needed by the client or her children 
in addition to the service need that brought her to the clinic. The instrument: (1) indicates the services the client came for; (2) assesses additional service needs; and (3) records the services, appointments, and referrals provided. The screening instruments used in each site followed the same basic form, but the content varied according to available services and clinic organization. Screening for family planning was included in all countries, and several checklists also screened for prenatal care, vaccinations, and general curative care. The simple checklist used in urban and rural health posts in Senegal is shown in Figure 1.

\section{Figure 1.}

\section{Short screening checklist used in Senegal}

\begin{tabular}{|c|c|c|c|c|}
\hline \multirow{2}{*}{\multicolumn{2}{|c|}{$\begin{array}{l}\text { To be filled in by screener } \\
\text { Client's age }\end{array}$}} & \multirow{2}{*}{\multicolumn{3}{|c|}{ Principal reason for visit }} \\
\hline & & & & \\
\hline \multirow{2}{*}{\multicolumn{2}{|c|}{$\begin{array}{l}\text { Before the consultation, always } \\
\text { ask the client if, in addition to } \\
\text { the principal reason for her visit, } \\
\text { she would like to receive one } \\
\text { of the following services (circle } \\
\text { number) }\end{array}$}} & \multicolumn{3}{|c|}{$\begin{array}{l}\text { After the consultation, always note the } \\
\text { result of the visit (write the number of } \\
\text { the corresponding code) }\end{array}$} \\
\hline & & \multirow[t]{2}{*}{$\begin{array}{c}1 \\
\text { Offered }\end{array}$} & \multirow[t]{2}{*}{$\begin{array}{c}2 \\
\text { Appointment }\end{array}$} & \multirow[t]{2}{*}{$\begin{array}{c}3 \\
\text { Referral }\end{array}$} \\
\hline 1 & Prenatal consultation & & & \\
\hline 2 & Vaccination for tetanus & & & \\
\hline 3 & Postnatal consultation & & & \\
\hline 4 & Family planning & & & \\
\hline 5 & $\begin{array}{l}\text { Screening or treatment for } \\
\text { RTI/STI }\end{array}$ & & & \\
\hline 6 & Vaccination of child & & & \\
\hline 7 & Growth monitoring of child & & & \\
\hline
\end{tabular}

Source: Sanogo et al. 2005.

\section{Results}

Systematic screening increased program output. In three of the four studies, the intervention increased the number of health services clients received per clinic visit. All differences were statistically significant $(\mathrm{p}<0.001)$. The only study that failed to increase the number of services provided to clients was in Honduras, where the local counterpart organization was unable to implement the intervention. As shown in Table 1, percent increases in the number of services received per client were large in almost all studies.
Frontiers in Reproductive Health Program Brief No. 6

Author: James R. Foreit

Editors: Stephanie Joyce, Laura Raney

Design: Vincent Hughes Visualization The assistance of the following reviewers is appreciated: Patricia Stephenson, Elizabeth Warnick, and John Townsend.

The photo on page 5 was selected from Photoshare at www.photoshare.org

Suggested citation: Foreit, James R. 2006. "Systematic screening: A strategy for determining and meeting clients' reproductive health needs," FRONTIERS Program Brief No. 6.

Washington, DC: Population Council.

The Frontiers in Reproductive Health Program (FRONTIERS) applies systematic research techniques to improve delivery of family planning and reproductive health services and influence related policies. FRONTIERS is funded by the U. S. Agency for International Development (USAID) and led by the Population Council in collaboration with Family Health International.

This publication was made possible through support provided by USAID under the terms of Cooperative Agreement No. HRN-A-00-98-00012. The opinions expressed herein do not necessarily reflect the views of USAID. (C) 2006 the Population Council, Inc. This publication may be reproduced in whole or in part without permission of Population Council provided full source citation is given and the reproduction is not for commercial purposes.

ISSN 1546-6612 
These findings show that integration at the provider level, when assisted by a screening instrument, can reduce unmet service needs. The similarity of the results across programs, regions and countries indicates that the findings are robust, and that systematic screening can be effective in a variety of settings.

In India the effectiveness of systematic screening, measured by the comparison between intervention and control clinics on the number of services received per clinic visit, was striking. The study was conducted during the back-to-back Hindu festivals of Diwali, Dussehra, and Navratri, when the ratio of services to visits declines (probably due to providers taking time off during the festivals). Even so, as seen in Table 2, the ratio of services to visits declined in all the control clinics, but increased in all the intervention clinics.

Most identified unmet needs resulted in additional services.

Most women requested the needed services that were detected during the intervention, and experimental clinics were able to satisfy most requests during the same client visit. In Bolivia, 89 percent of all detected needs resulted in the delivery of additional services, while in India

Table 1.

Percent increase in the number of services clients received per clinic visit after systematic screening interventions

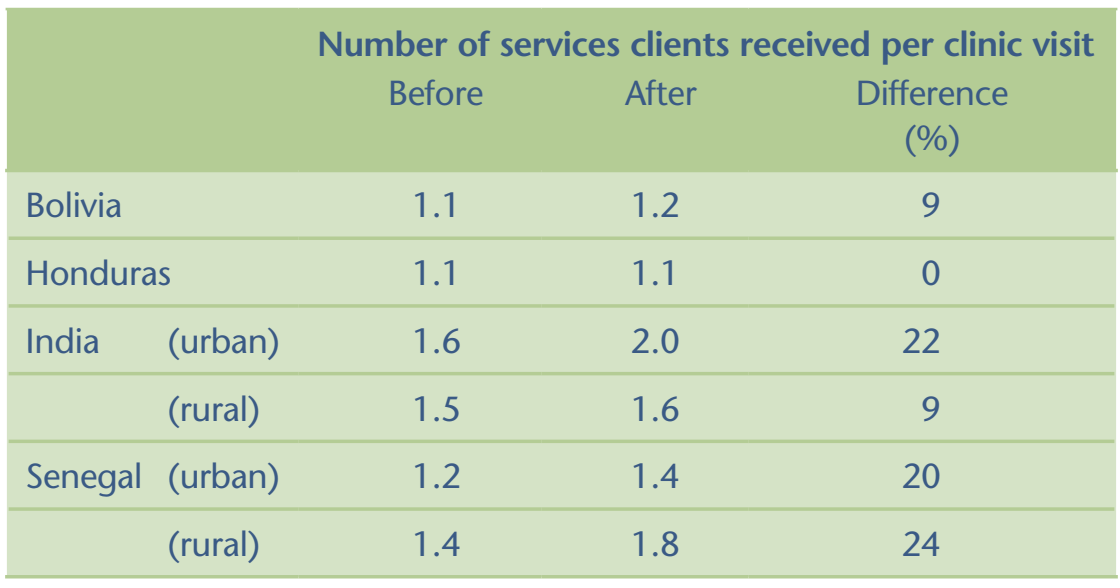

Foreit, Vernon, and Riveros 2005; Vernon et al. 2005; Das et al. 2005; and Sanogo et al. 2005.

Table 2.

\section{Percent change in the number of services clients received per clinic visit after systematic screening in India}

\begin{tabular}{|c|c|c|c|c|c|c|}
\hline \multirow[t]{3}{*}{ India } & \multicolumn{6}{|c|}{ Number of services clients received per clinic visit } \\
\hline & \multicolumn{3}{|c|}{ Control group } & \multicolumn{3}{|c|}{ Experimental group } \\
\hline & Before & After & $\begin{array}{c}\text { Difference } \\
(\%)\end{array}$ & Before & After & $\begin{array}{l}\text { Difference } \\
(\%)\end{array}$ \\
\hline Urban Clinics & 1.79 & 1.53 & -15 & 1.64 & 2.00 & 22 \\
\hline Rural Posts & 1.62 & 1.36 & -16 & 1.48 & 1.61 & 9 \\
\hline
\end{tabular}

Das et al. 2005 .

96 percent resulted in additional services. The impact of screening on the increased use of family planning services was high in India. The increase in total services per visit was driven by the provision of more family planning services to women who visited the clinic for the vac- cination of their children. The use of family planning services increased by 53 percent-the largest component of the overall increase in services per visit (Das et al. 2005). 


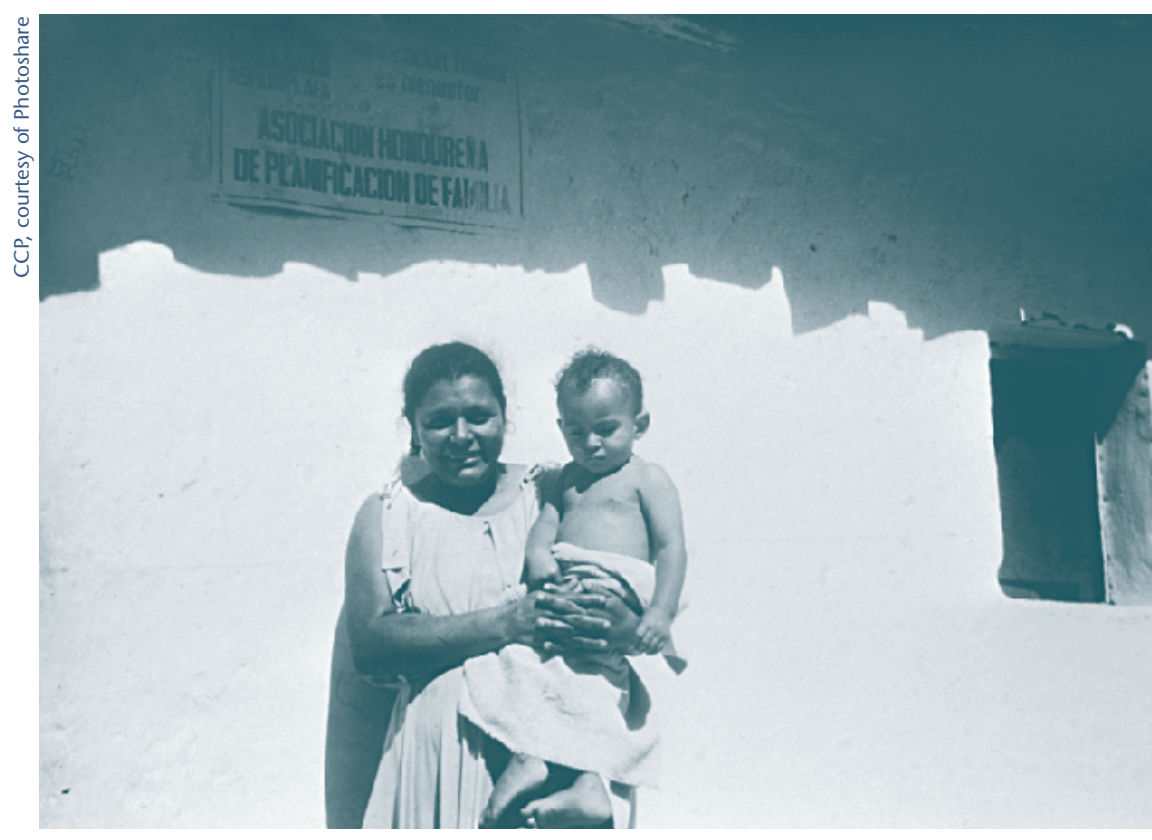

A woman stands outside a family planning clinic in Honduras

\section{Factors affecting the effectiveness of screening}

Provider compliance determined the overall effectiveness of screening.

In Honduras, only 11 percent of clients were screened, and in Bolivia only 45 percent of clients were screened. Low levels of screening resulted in little benefit in Honduras and reduced the potential effectiveness of the intervention in Bolivia.

Since fewer than half of all visits made during the post-intervention period were screened in Bolivia, a comparison was made of services per visit for screened and non-screened clients. This analysis presents a picture of the screened 71 percent of clients. In Honduras, failure to screen clients was largely the result of problems with provider motivation. Many providers did not screen because they did not feel it was important, and immediate supervisors did not provide reinforcement or follow-up.

\section{The studies identified} techniques that may help overcome compliance problems.

Using a shorter form that screens for fewer unmet needs may increase screening in highly utilized services or in facilities with few available services, such as in Bolivia. In Senegal, both short and long screening forms were tested. The shorter form, which was quicker to apply, resulted in the provision of as many additional services as did the longer form. The results suggest that shorter checklist formats can screen as effectively as longer questionnaire formats.

Motivational problems of staff may be overcome by creative supervision solutions. For example, health officials in Senegal appointed one staff member in each site to be responsible for screening in her facility. Higher motivation may also be associated with longer training in the systematic screening technique. In both India and Senegal, providers received more than two days of training, while in Honduras, training lasted less than a half-day. Also in Senegal, the support of village health 
committees was obtained in the implementation of the intervention.

\section{Systematic screening improves productivity.}

The increase in the number of services provided per visit implies an improvement in provider productivity. Providing multiple services during the same visit also benefits the client by reducing her opportunity and financial costs. In rural areas, where the unmet need for reproductive health services is high, and provider productivity low, screening is an effective and costeffective alternative to outreach services.

\section{Utilization Of Results}

Based on these studies, health authorities in Bolivia, India, and Senegal wish to scale up systematic screening, while the Honduras program will try a second time to implement the strategy. In Bolivia, plans include scaling up with the support of USAID mission funds and technical assistance from the Population Council, CARE, and John Snow Inc. through the bilateral project "Mejorar la Salud de Los Bolivianos [Improving the Health of Bolivians]."

In India, the Vadodara municipal government announced that it would scale up the intervention from the four pilot clinics to its remaining 10 clinics in the city, while the health system in the state of Gujarat will initiate the intervention in two rural districts encompassing over 50 clinics.

The Senegalese Ministry of Health has asked FRONTIERS to assist with scale-up in three regions comprising 19 districts with a focus on compliance and sustainability. In Honduras, the Honduran Family Planning Association (Asociación Hondureña de Planificación de la Familia, ASHONPLAFA) will use its own funds to implement the intervention again, building on lessons learned.

The request to scale up systematic screening within three programs provides FRONTIERS with the opportunity to conduct several short studies while assisting in the large-scale implementation of the technique. The scale-up also offers a chance to

\section{Conclusion}

Studies in Bolivia, Honduras, India, and Senegal indicate that systematic screening is an effective strategy for increasing integration, as measured by the number of services received per client visit. Increases were significant, ranging from 9 to 24 percent, depending on the clinic type, locale, and degree of provider compliance. Increases of this magnitude, if replicable, could make a major impact on the outputs of large service programs, and could potentially result in improvements in the health status of women and children. test interventions to overcome provider compliance problems-problems that affect the implementation of all new techniques and job aids shown to improve program performance. FRONTIERS will provide support for scaling up with operations research to: (1) estimate the costs of implementing the intervention on a large scale; (2) monitor the effectiveness of systematic screening once it is introduced into a broader program setting; and (3) improve provider compliance with new service delivery innovations.

As a result of these FRONTIERS OR studies, USAID has identified the systematic screening technique as a priority best practice, and plans its replication in other countries. FRONTIERS is developing a training manual to assist with the utilization of systematic screening. 


\section{References}

Das, N. P. et al. 2005. "Systematic screening to meet unmet need by integrating reproductive health services: An operations research model to maximize service utilization," FRONTIERS Final Report. Washington, DC: Population Council.

Foreit, James R. et al. 2003. "FRONTIERS operations research protocols: Providing more preventive reproductive health care through systematic screening," FRONTIERS Report. Washington, DC: Population Council.

Foreit, James R., Ricardo Vernon, and Patricia Riveros. 2005.

"Use of systematic screening to increase the provision of reproductive health services in Bolivia," FRONTIERS Final Report. Washington, DC: Population Council.

Foreit, Karen G. Fleischman, Karen Hardee, and Kokila Agerwal. 2002. "When does it make sense to consider integrating STI and HIV services with family planning services?" International Family Planning Perspectives 28(2): 105-107.

León, Federico et al. 1998. "Increasing use of reproductive health services in a Peruvian clinic," in Family Planning Operations Research: A Book of Readings, J. Foreit and T. Frejka (eds.). New York: Population Council, pp. 239-245.
Ministry of Health and Population Council. 1998. "Evolution des services de santé de la reproduction et de planification familiale de 1994 à 1998 [The evolution of reproductive health and family planning services from 1994 to 1998 (Senegal)]," Africa OR/TA II Rapport Final. Projet de Recherche Operationnelle et d'Assistance Technique en Afrique II. Dakar: Ministère de la Santé, Program National de Planification Familiale et Population Council.

Sanogo, D. et al. 2005. "Using systematic screening to increase integration of reproductive health services delivery in Senegal," FRONTIERS Final Report. Washington, DC: Population Council.

Vernon et al. 2005. "Systematic screening as a strategy to increase services integration and revenues in Honduras," FRONTIERS Final Report. Washington, DC: Population Council.

Vernon, Ricardo and James Foreit. 1999. "How to help clients obtain more preventative reproductive health care." International Family Planning Perspectives 25(4): 200-202. 
The Population Council is an international, nonprofit, nongovernmental institution that seeks to improve the wellbeing and reproductive health of current and future generations around the world and to help achieve a humane, equitable, and sustainable balance between people and resources.

The Council conducts biomedical, social science, and public health research and helps build research capacities in developing countries. Established in 1952, the Council is governed by an international board of trustees. Its New York headquarters supports a global network of regional and country offices.

The Frontiers in Reproductive Health Program (FRONTIERS) applies systematic research techniques to improve delivery of family planning and reproductive health services and influence related policies. FRONTIERS is funded by the U. S. Agency for International Development (USAID) and led by the Population Council in collaboration with Family Health International.

Frontiers in Reproductive Health Program (FRONTIERS) Population Council 4301 Connecticut Avenue, NW, Suite 280

Washington, DC 20008

Telephone: (202) 237-9410

Facsimile: (202) 237-8410

E-mail: frontiers@pcdc.org www.popcouncil.org/frontiers

This publication was made possible through support provided by USAID under the terms of Cooperative Agreement No. HRN-A-00-98-00012. The opinions expressed herein do not necessarily reflect the views of USAID.

\section{(c) 2006 the Population Council, Inc.}

This publication may be reproduced in whole or in part without permission of Population Council provided full source citation is given and the reproduction is not for commercial purposes. 